\title{
The Impact of pH and Air on the Phospholipid Nanostructure Surface
}

\author{
M. Sojka1,2, Z. Pawlak ${ }^{3,4^{*}}$ \\ ${ }^{1}$ Mechanical Department, Kujawy University, Grudziadz, Poland \\ ${ }^{2}$ CORSAR Engineering Industry, Glogowa 2, Poland \\ ${ }^{3}$ Tribochemistry Consulting, Salt Lake City, UT 84117, USA \\ ${ }^{4}$ Biotribology Lab, University of Economy, Bydgoszcz, Poland \\ Email: *zpawlak@xmission.com
}

How to cite this paper: Sojka, M. and Pawlak, Z. (2021) The Impact of $\mathrm{pH}$ and Air on the Phospholipid Nanostructure Surface. Open Journal of Orthopedics, 11, 392-398 https://doi.org/10.4236/ojo.2021.1112037

Received: October 21, 2021

Accepted: December 27, 2021

Published: December 30, 2021

Copyright (c) 2021 by author(s) and Scientific Research Publishing Inc. This work is licensed under the Creative Commons Attribution International License (CC BY 4.0).

http://creativecommons.org/licenses/by/4.0/ (c) (i) Open Access

\begin{abstract}
Phospholipids (PLs) in the form of nanostructures are widely employed as a lubricant and antimicrobial agent. The cartilage (AC) surface was characterized using wettability test fresh and depleted AC samples. Cartilage wet surface exposure to air causes increase in surface wettability from 0 to $104 \mathrm{de}$ grees. Effect is explained by flip-flop of the PLs molecules in membrane. The hydrophilic and hydrophobic character of cartilage was determined. Microscopic image of PLs bilayers adsorbed on the surface of pleural tissues and human stomach will be compared with cartilage tissue.
\end{abstract}

\section{Keywords}

PLs Bilayers, Wettability, PLs Flip-Flop, Pleural, Cartilage Surface, Human Stomach Tissue

\section{Introduction}

The phospholipids (PLs) in human body [1] [2] create bilayers and multilayer structures in many places where friction occurs (see Figs. below). The past two decades Hills introduced pioneer model joint lubrication with phospholipid multi-bilayers as lubricant the surface amorphous layer (SAL). The amphoteric cartilage surface in aqueous media is hydrophilic with wettability $\sim 0^{\circ}$ and in dry-air condition is hydrophobic with wettability $104^{\circ}$ [2]. Hills' lubrication model was well documented by microscopic image of PLs bilayers adsorbed on the surface of (a) pleural tissues, (b) knee joint, (c) human stomach [3] and by analytical determination PLs bilayer numbers on tissue surfaces.

Phospholipids as lubricants are spontaneously self-assembled biomolecules in 
an aqueous environment and their structures (hydrophilic/hydrophobic) allow the formation of liposomes, lamellar phases, and membranes (Figure 1). The (SAL) with porosity ( $75 \%$ to $80 \%$ ) covers the cartilage, which ensures excellent moisturizing (hydrating) properties.

Surface-active phospholipid molecules (SAL) adsorbed on the articular cartilage on the negatively charged proteoglycan layer form a phospholipid multibilayer (membrane). The PL bilayer has a negatively charged surface $\left(-\mathrm{PO}_{4}^{-}\right)$and is hydrophilic at $\mathrm{pH} \sim 7.4$.

The Hills' hydrophobic model has been reviewed as erroneous, which will be based on current research [2]. The hydrophobic AC surface has not gained any support in experimental facts and current literature showing that $\mathrm{AC}$ is amphoteric and hydrophilic with a negatively charged surface $\left(-\mathrm{PO}_{4}^{-}\right)[2]$.

The surface energy of the model membrane of spherical lipid bilayer vs. $\mathrm{pH}$ defends amphoteric property and has the course of the "bell curve" with maximum IEP at $\mathrm{pH} \sim 4.0$ and the lowest surface energy in the natural joints for $\mathrm{pH}$ 6.5 to 9.0 [2].

This part of the study aimed to show that the wettability of the amphoteric surface of phospholipid bilayers is changing and is an essential parameter of this tissue. Phospholipid bilayers adsorbed on the surface of articular cartilage reduce friction to surprisingly low values [2] [3] [4]. The surface in many animal organs is capable of adsorbing the surface-active phospholipids as a barrier against adhesion, corrosion, and microorganisms and in the case of cartilage, the phospholipids are involved in the lubrication. The surface so coated has a different wettability depending on the number of bilayers [2] [3].

In this paper, we examine wettability of bovine cartilage (BC) surface in airdry condition.

\section{Experimental}

The articular cartilage specimens were collected from bovine knees aged $\sim 1.5$ years. Osteochondral plugs, of $10 \mathrm{~mm}$ in diameter, were harvested from lateral and medial femoral condyles. The cartilage discs were cut into 3-mm plugs with full attachment to the underlying bone. The specimens were stored at $253 \mathrm{~K}$ in $0.155 \mathrm{M} \mathrm{NaCl}(\mathrm{pH}=6.9)$ and fully defrosted prior to testing.

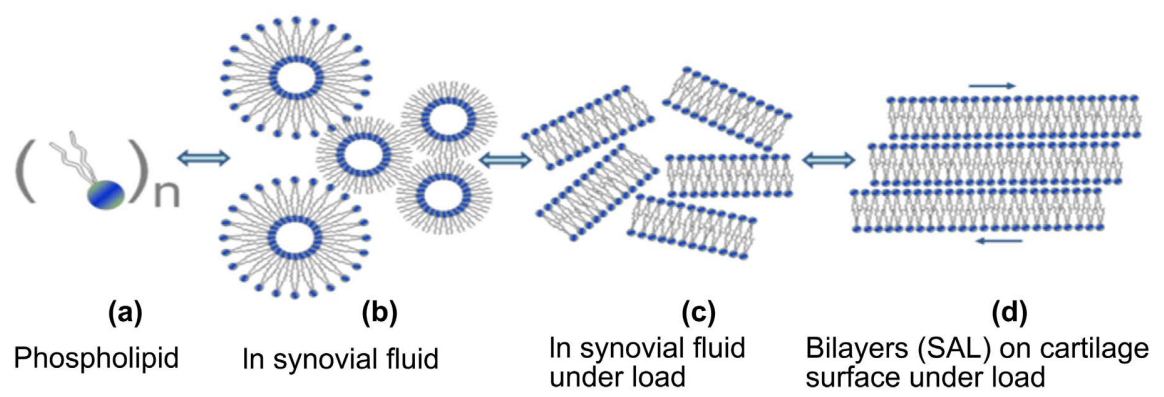

Figure 1. Phospholipid equilibrium processes (a) solid phase phospholipids; (b) liposomes and hexagonal phases in synovial fluid; (c) lamellar phases in synovial fluid under load; and (d) phospholipid bilayers on the cartilage surface under load [2]. 


\section{Wettability Measurements}

A KSV CAM100 computerized tensiometer was used to measure the contact angle of cartilage samples. A drop of the $0.155 \mathrm{M}$ saline solution was deposited on the air-dry cartilage surface. The tests on the normal, partial and completely depleted cartilage samples were repeated five times. Delipidation operation is the removal of lipids from cartilage surface using (chloroform/methanol $(2: 1, \mathrm{v} / \mathrm{v})$.

\section{Results and Discussion}

After evaporation of water from the cartilage surface, the phosphate groups $\left(-\mathrm{PO}_{4}^{-}\right)$are deactivated as a result of conformational changes on the surface (flipflop) of phospholipid molecules, Figure 2(b), Figure 2(c). Hydrophilic bilayer Figure 2(b) in wet state and after air-dry time turns into a hydrophobic monolayer. The results obtained for all wettability test are presented in Figure 2(d): Curve: 1) after 19-minute cartilage delipidation (chloroform/methanol (2:1, v/v),<smiles>[R]C(=O)OCC(COP(=O)([O-])OCC[N+](C)(C)C)OC([R])=O</smiles>

(a)

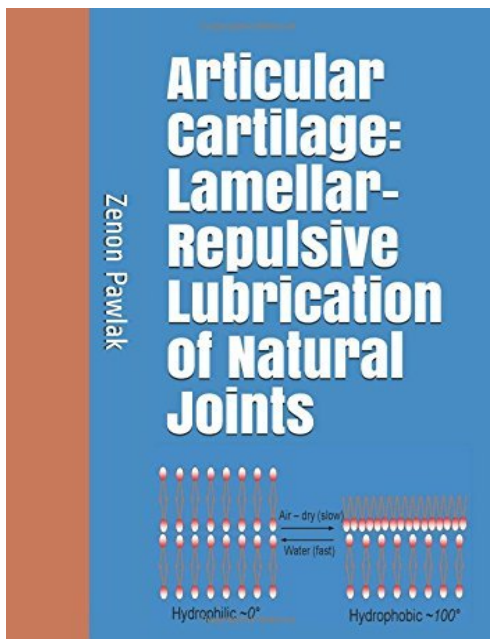

(b) 


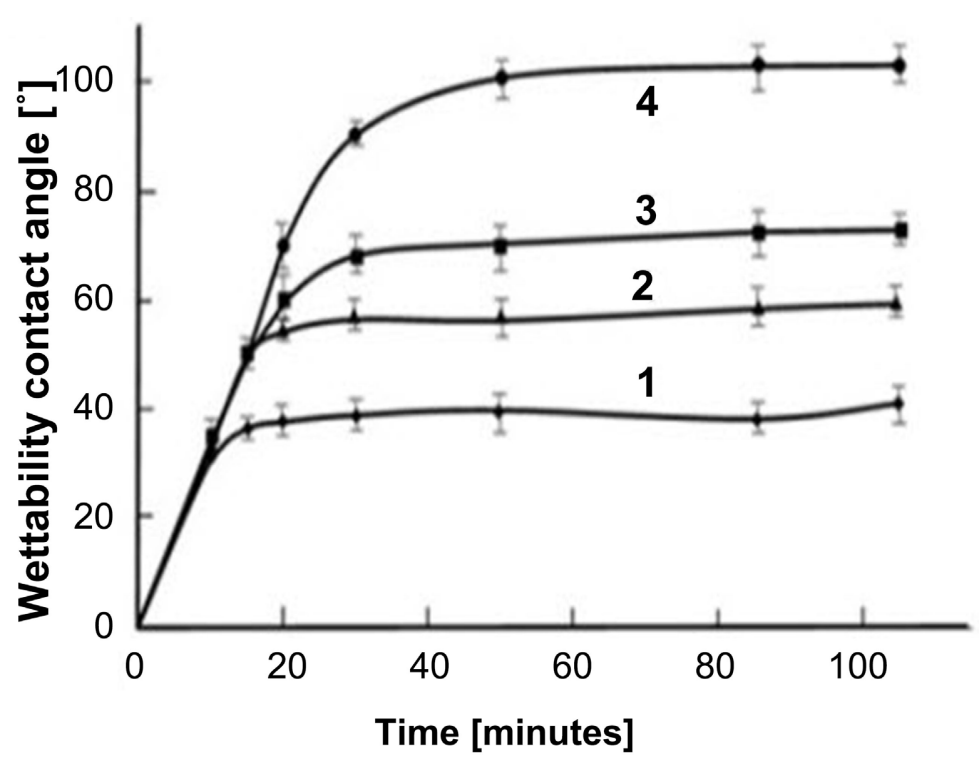

(c)

Figure 2. The phospholipid bilayers of articular cartilage surface in the wet and air-dry condition. (a) General structural formula of phosphatidylcholines. The book covers with transformation scheme; (b) in wet state is hydrophilic $\sim 0^{\circ}$ wettability and after air-dry is hydrophobic $\sim 104^{\circ}$ wettability; (c) after air-drying; (d) wettability vs. time in the openair. Air-dried cartilage samples $(n=5)$, mean value, $95 \%$ confidence level.

contact angle is $40^{\circ}$;2) after 9 minutes of delipidation, contact angle $63^{\circ}, 3$ ) after 3 minutes of delipidation, contact angle is $\left.73^{\circ}, 4\right)$ the contact angle of the healthy cartilage surface is $104^{\circ}$. The degradation of the surface of bovine cartilage from super hydrophilic (contact angle $\sim 0^{\circ}$ ) to a hydrophobic monolayer is expressed by an increase in surface energy [2].

Poor lubrication in animal joints, particularly on the articular surface of cartilage, can be attributed to deterioration of the bilayer surface, where the wettability or contact angle $(\theta)$ changes from $\sim 100^{\circ}$ (healthy) to less than $70^{\circ}$ (unhealthy).

The smart-surface of articular cartilage constitution of the superficial phospholipid bilayer in (a) aqueous electrolyte solution and (b) air-dry conditions. A change in surface energy leads to conformational changes in the surface of the bovine patella from bilayer (super hydrophilic $\sim 0^{\circ}$ contact angle) to monolayer (hydrophobic $\sim 100^{\circ}$ ).

Figure 3 shows microscopic images of the stomach, cartilage and pleural surfaces [3]. In the case of the stomach with several bilayers for $\mathrm{pH}<1$ and strong adsorption of phosphatidylcholine quaternary ammonium ion $(\mathrm{Me})_{3} \mathrm{~N}^{+}$-) (see Figure 2(a) for general structural formula of phosphatidylcholines), which interacts with the negatively charged surface of the stomach and forms a hydrophobic monolayer on the surface. A consistent phospholipid monolayer with a $\mathrm{Ca}$ (II) bond between groups (- $\mathrm{PO}_{4}^{-}$) is created. Consistency of phospholipids at a very low $\mathrm{pH}$ prevailing in the stomach becomes a necessity, Figure 4(a) [5] [6].

The formation of a hydrophobic monolayer was observed in the presence of 


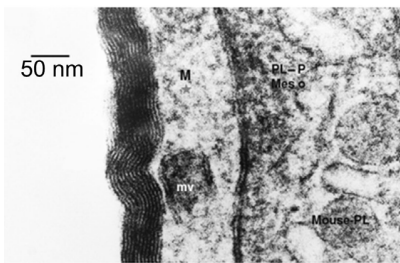

(a)

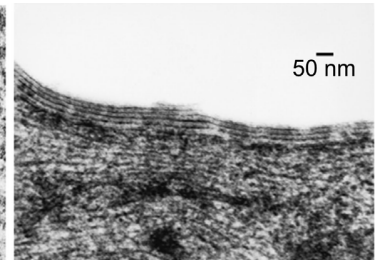

(b)

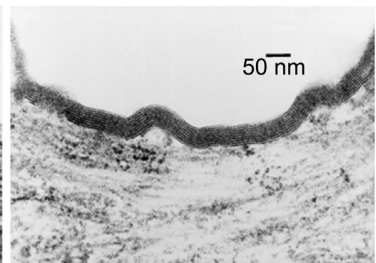

(c)

Figure 3. Microscopic image of PLs bilayers adsorbed on the surface of (a) pleural tissues; (b) knee joint; (c) human stomach.

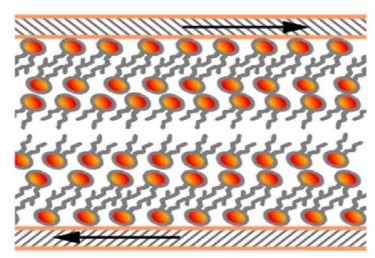

In water

(a)

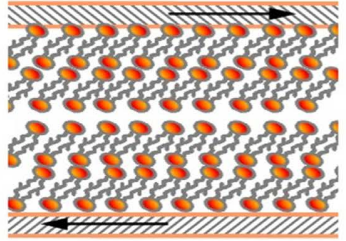

In water

(b)

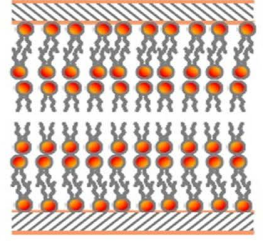

In air

(c)

Figure 4. Model of natural boundary lubrication of surfaces based on phospholipid bilayers, (a) hydrophobic model of the stomach at very low $\mathrm{pH}<1$; (b) hydrophilic model of the negatively charged surface of cartilage for $\mathrm{pH} 7.4$; (c) hydrophobic model of the pleural in the presence of air phase for $\mathrm{pH} 7.4$ [7].

an air/liquid phase at $\mathrm{pH} 7.4$ for the pleural and for $\mathrm{pH}<1$ for the stomach (see Figure 4(c) and Figure 4(a). The model in Figure 4(c) shows pleural surfaces with a thin layer of tightly packed hydrocarbon chains comparable to that of a hydrophobic stomach. Figure 4(b) presents the surface of the cartilage with a hydrophilic bilayer structure.

The stomach model shown in Figure 4(c) has the following characteristics:

- The hydrophobic protective phospholipid monolayer is the physical barrier called by Davenport [8] "gastric mucosal barrier";

- PL molecules are directly adsorbed on the surface of the gastric mucosa, originally attached by electrostatic attraction between the of phosphatidylcholine quaternary ammonium ion $(\mathrm{Me})_{3} \mathrm{~N}^{+}$) and the negatively charged membrane. The mean angle of wettability is $85^{\circ}$ for the surface of the gastric mucosa [1] [9].

The phospholipid monolayer adsorbed on the surface of the mucous membrane contains a protonated phosphate group $\left(-\mathrm{PO}_{4} \mathrm{H}\right)$ that is not ionized in the stomach at $\mathrm{pH}<1$, but is ionized at physiological $\mathrm{pH} 7.4$ (see equation below) [4].

$$
\begin{aligned}
& \left(\mathrm{Me}_{3} \mathrm{~N}^{+}\right)\left(\mathrm{CH}_{2}\right)_{2} \mathrm{PO}_{4} \mathrm{H}-\mathrm{R}_{1} \mathrm{R}_{2} \rightleftarrows\left(\mathrm{Me}_{3} \mathrm{~N}^{+}\right)\left({ }^{-} \mathrm{OH}\right)\left(\mathrm{CH}_{2}\right)_{2} \mathrm{PO}_{4}^{-}-\mathrm{R}_{1} \mathrm{R}_{2} \\
& \mathrm{pH}<1 \quad \mathrm{pH} 7.4
\end{aligned}
$$

The amine functional group of phosphatidylethanolamine (PE) for $\mathrm{pH} 7.4$ is uncharged by a functional group $\left.\left(-\mathrm{NH}_{2}\right):\left(-\mathrm{NH}_{3}^{+}\right)+\mathrm{OH}^{-} \rightarrow-\mathrm{NH}_{2}+\mathrm{H}_{2} \mathrm{O}\right)$. In the case of phosphatidylcholine, a quaternary ammonium ion for $\mathrm{pH} 7.4$ will form ion pair with hydroxide ion $\left(\mathrm{Me}_{3} \mathrm{~N}^{+}-\mathrm{OH}^{-}\right)$and will be adsorbed or electrostati- 
cally interact with the hydrophilic surface; the ion pair association constant is: $\mathrm{K}_{\text {ass }} \sim 5 \times 10^{5}$ [10]. Strong adsorption and cohesion are essential parameters for surface-active phospholipids with a strong adsorption of cationic quaternary ammonium ion (QA) on the hydrophilic surface and the presence of the phosphate-bond cohesive barrier with the Ca (II) cation.

According to Linn and Sokoloff [11] "the secret of low friction (cartilage/cartilage) is the fact that the surfaces do not touch" and phospholipids participate in the lamellar lubrication mechanism [12]. Phospholipids are spontaneously selfassembled biomolecules in liposomes and under load (pressure) transformed in lamellar phases bilayers and membrane (see Figure 1). The phospholipid bilayers on the surface of the cartilage are called the surface amorphous layer (SAL). A negatively charged surface by phospholipid group $\left(-\mathrm{PO}_{4}^{-}\right)$and very high cartilage porosity ( $75 \%$ to $80 \%$ ) provides excellent hydration properties of the articular cartilage [1]. Hydrophilic cartilage surfaces are negatively charged, they repel electrostatically with the participation of lamellar PLs phases (see Figure 1), the glycoprotein lubricin, hydrated hyaluronan macromolecules are under almost instant contactless pressure [13].

\section{Conclusion}

In this work, we demonstrated that PLs the stomach membrane surfaces at $\mathrm{pH}<$ 1 are hydrophobic uncharged, and at $\mathrm{pH} \sim 7$ cartilage is hydrophilic and negatively charged, and pleural surface is hydrophobic at air condition. The cartilage surface was characterized using wettability test fresh and depleted AC samples.

\section{Conflicts of Interest}

The authors declare no conflicts of interest regarding the publication of this paper.

\section{References}

[1] Hills, B.A. (1988) The Biology of Surfactant. Cambridge University Press, London.

[2] Pawlak, Z. (2018) Articular Cartilage: Lamellar-Repulsive Lubrication of Natural Joints. KDP. Print-Book: https://www.amazon.com/dp/1976760283 e-book: https://www.amazon.com/dp/B07B42P1JY

[3] Hills, B.A. (2002) Surface-Active Phospholipid: A Pandora's Box of Clinical Applications, Part II. Barrier and Lubricating Properties. Internal Medicine Journal, 32, 242-251. https://doi.org/10.1046/j.1445-5994.2002.00201.x

[4] Hills, B.A and Butler, B.D. (1984) Surfactants Identified in Synovial Fluid and Their Ability to Act as Boundary Lubricants. Annals of the Rheumatic Diseases, 43, 641648. https://doi.org/10.1136/ard.43.4.641

[5] Mreła, A. and Pawlak, Z. (2019) Articular Cartilage. Strong Adsorption and Cohesion of Phospholipids with the Quaternary Ammonium Cations Providing Satisfactory Lubrication, of Natural Joints. Biosystems, 176, 27-31. https://doi.org/10.1016/j.biosystems.2018.12.005

[6] Mreła, A. and Pawlak, Z. (2018) Articular Cartilage: Chemical, Physical, and Tribological Properties. Journal of New Developments in Chemistry, 1, 7-11.

https://doi.org/10.14302/issn.2377-2549.jndc-18-2159 
[7] Mreła, A. and Pawlak, Z. (2018) Articular Cartilage: Amphoteric Nature and Interfacial Energy. Journal of Clinical and Molecular Medicine, 1, 1-2. https://doi.org/10.15761/JCMM.1000114

[8] Davenport, H.W. (1965) Is the Apparent Hyposecretion of Acid by Patients with Gastric Ulcer a Consequence of Broken Barrier to Diffusion of Hydrogen Ions into the GASTRIC mucosa? Gut, 6, 513. https://doi.org/10.1136/gut.6.5.513

[9] Hills, B.A. and Crawford, R.W. (2003) Normal and Prosthetic Synovial Joints Are Lubricated by Surface-Active Phospholipid: A Hypothesis. Journal of Arthroplasty, 18, 499-505. https://doi.org/10.1016/S0883-5403(03)00072-X

[10] Petelska, A.D. and Figaszewski, Z.A. (2002) Effect of $\mathrm{pH}$ on the Interfacial Tension of Bilayer Lipid Membrane Formed from Phosphatidylcholine or Phosphatidylserine. Biochimica et Biophysica Acta (BBA)_Biomembranes, 1561, 135-146. https://doi.org/10.1016/S0005-2736(01)00463-1

[11] Linn, F.C. and Sokoloff, L. (1965) Movement and Composition of Interstitial Fluid of Cartilage. Arthritis and \& Rheumatism, 8, 481-494. https://doi.org/10.1002/art.1780080402

[12] Mrela, A. and Pawlak, Z. (2018) Hydrophilic and Charged Cartilage Surface for Reducing the Friction Coefficient. Frontiers in Nanoscience and Nanotechnology, 4, 1-3. https://doi.org/10.15761/FNN.1000175

[13] Israelachvili, J.N. and Wennerstrom, H. (1996) Role of Hydration and Water Structure in Biological and Colloidal Interactions. Nature, 379, 219-225.

https://doi.org/10.1038/379219a0 